\title{
Cigarette smoking, health status, socio-economic status and access to health care in diabetes mellitus: a cross-sectional survey MC Gulliford*, JEC Sedgwick and AJ Pearce
}

\author{
Address: Department of Public Health Sciences, King's College London, Capital House, 42 Weston St, London SE1 3QD, UK \\ Email: MC Gulliford* - martin.gulliford@kcl.ac.uk; JEC Sedgwick - james.sedgwick@doctors.org.uk; AJ Pearce - a.pearce@warwick.ac.uk \\ * Corresponding author
}

Published: II February 2003

BMC Health Services Research 2003, 3:4

This article is available from: http://www.biomedcentral.com/I472-6963/3/4

(c) 2003 Gulliford et al; licensee BioMed Central Ltd. This is an Open Access article: verbatim copying and redistribution of this article are permitted in all media for any purpose, provided this notice is preserved along with the article's original URL.

\begin{abstract}
Background: In diabetes mellitus, cigarette smoking is associated with increased risk of cardiovascular mortality and microvascular complications. We evaluated cigarette smoking in people with diabetes mellitus in a socio-economically deprived area.

Methods: We carried out a cross-sectional survey of people registered with diabetes mellitus at 29 general practices in inner London. Responses were analysed for I,899 (64\%) respondents out of 2,983 eligible.

Results: There were I,899 respondents of whom 968 (5I\%) had never smoked, 296 (16\%) were current smokers and $582(31 \%)$ were ex-smokers. Smoking was more frequent in white Europeans (men 22\%, women 20\%), than in African Caribbeans (men 15\%, women 10\%) or Africans (men $8 \%$, women $2 \%$ ). Smoking prevalence decreased with age. Smokers were more likely to be living in rented accommodation (odds ratio, OR 2.02, 95\% confidence interval I.48 to 2.74). After adjusting for confounding, current smokers had lower SF-36 scores than subjects who had never smoked (mean difference in physical functioning score $-5.6,95 \%$ confidence interval -10.0 to -1.2 ; general health $-6.1,-9.7$ to -2.5$)$. Current smokers were less likely to have attended a hospital diabetic clinic in the last year (OR $0.59,0.44$ to 0.79 ), and their hypertension was less likely to be treated (OR $0.47,0.30$ to 0.74 ).

Conclusions: Compared with non-smokers, smokers had lower socio-economic status and worse health status, but were less likely to be referred to hospital or treated for their hypertension. People with diabetes who smoke can be regarded as a vulnerable group who need more intensive support and treatment.
\end{abstract}

\section{Background}

There is a high risk of cardiovascular disease in people with diabetes, but there is an interactive effect of cigarette smoking which greatly increases cardiovascular risk in people with diabetes who smoke $[1,2]$. One study estimated that $65 \%$ of cardiovascular deaths in diabetes were explained by the interaction between cigarette smoking and diabetes [2]. Cigarette smoking also increases the risk of microvascular disease in diabetes. Haire-Joshu et al [3] systematically reviewed analytical studies and found that there was strong evidence for an association between smoking and nephropathy, moderate evidence for an association with neuropathy, but less consistent evidence for an association with retinopathy. 
Some studies in diabetes suggest that lower socio-economic status is associated with a higher prevalence of diabetes [4-6], and an increased frequency of diabetic complications $[7,8]$. Cigarette smoking in the general population shows a pronounced social class gradient. Data from the Health Survey for England show that 15\% of men and $14 \%$ of women in social class I smoke, compared with $42 \%$ of men and $37 \%$ of women in social class $\mathrm{V}$ [9]. Cigarette smoking is now recognised as an important contributor to social inequalities in health in the general population $[10,11]$. Cigarette smoking may also contribute to inequity because smokers might not gain the same access to health care compared with non-smokers. There is some evidence that general practitioners' treatment and referral decisions may be influenced unfavourably by smoking status $[12,13]$.

There is little information available on the distribution of cigarette smoking in people with diabetes [3]. One report described data from the 1989 US National Health Interview Survey (NHIS) [14]. This showed that the age-adjusted prevalence of smoking was similar in people with diabetes $(27.3 \%$ smokers $)$ and without diabetes $(25.9 \%$ smokers). Equivalent data for the UK appear to be lacking. This report describes the characteristics of cigarette smokers in a primary care-based sample of people with diabetes in an inner city. We wanted to answer four questions. How common is smoking among people with diabetes in an inner city? What are the characteristics of diabetic subjects who smoke? How does the health of diabetic smokers compare with non-smokers? Is diabetes care accessed equitably by those who smoke and those who do not?

\section{Methods \\ Subjects}

The data were obtained from a study which evaluated ethnic and socio-economic inequalities in health and access to care in diabetes. The survey was carried out in 1999 in South East London. This area has a Jarman score of 44 consistent with a high level of deprivation, black and ethnic minority groups are estimated to make up about $30 \%$ of the total population. We estimated that we required a final sample size of 1600 in order to have $90 \%$ power to detect differences in health status measures between ethnic groups. We used a purposive sampling strategy in order to recruit a high proportion of ethnic minorities. All 175 general practices in three neighbouring inner London boroughs were contacted and invited to participate. Of the 95 responding practices, 79 of which agreed to participate, 29 were systematically selected from localities with a high proportion of resident ethnic minorities at the 1991 census [15]. All practices were in localities in which the proportion of ethnic minorities was $20 \%$ or more, 19 practices were in localities with $40 \%$ or more ethnic minorities. We compiled a list of subjects identified by these practices as having diabetes mellitus (usually from computerised registers). A self-completion questionnaire was mailed to each subject and returned in a pre-paid envelope. Two reminders were sent at approximately monthly intervals, the second with a further copy of the questionnaire. The study was approved by the local research ethics committee and all subjects gave written informed consent to participate.

\section{Questionnaire}

The questionnaire was developed, piloted and validated in a cross-cultural study of 375 patients attending a hospital diabetic clinic [16]. We included two questions concerning cigarette smoking: 'Have you ever smoked cigarettes for as long as a year?' and 'Do you smoke cigarettes now?'. Responses were used to classify subjects into 'current smokers', 'ex-smokers' and 'never-smokers'. We did not collect information about the duration of smoking, nor the number of cigarettes smoked per day. Subjects were defined as having type 1 diabetes if the condition was diagnosed before the age of 30 and required insulin treatment within the first year after diagnosis. The questionnaire included the UK version of the short form 36 (SF-36) [17] as a measure of health related quality of life. The questionnaire also included questions concerning morbidity from 'heart attack', 'stroke', 'other heart trouble', 'high blood pressure', 'difficulty with eyesight', 'burning or numbness in the feet', 'foot ulcer', or 'amputation' [18]. Questions concerning ethnicity, occupation, employment, housing tenure and car ownership were based on the 1991 UK census and the categories used are shown in table 1. Ethnicity was self-assigned from the categories: 'white', 'black-Caribbean', 'black-African', 'black-other', 'Indian', 'Pakistani', 'Bangladeshi', 'Chinese' and 'any other ethnic group'. For analysis, categories were reduced to 'white European', 'African Caribbean', 'African' and 'other and not known'. Each individual's occupational social class was assigned based their self-reported occupation and the Registrar General's classification [19]. For analysis, the categories were reduced to 'manual' or 'non-manual'. We also included questions concerning utilisation of diabetes care including whether diabetes was mainly looked after by a hospital doctor or a GP, how many times the patient had attended a GP or a hospital clinic in the last year, and whether the patient was currently taking tablets or medicines for high blood pressure. We also asked about the use of self-monitoring and the main treatments used for diabetes.

\section{Analysis}

Current smoking was tabulated by gender, age group, ethnicity and social variables. Variables associated with current smoking were identified by fitting a logistic regression model with robust variance estimates to allow for clustering by general practice [20]. Multiple linear 
Table I: Characteristics of diabetic subjects according smoking status. Figures are frequencies (percent of row total).

\begin{tabular}{|c|c|c|c|c|c|c|}
\hline & & $\begin{array}{l}\text { Never smoked } \\
(968)\end{array}$ & $\begin{array}{l}\text { Current smoker } \\
\text { (296) }\end{array}$ & $\begin{array}{l}\text { Ex-smoker } \\
(582)\end{array}$ & All & P value ${ }^{a}$ \\
\hline \multirow[t]{2}{*}{ Sex } & Men & $374(40)$ & $166(18)$ & 361 (39) & 928 & $<0.001$ \\
\hline & Women & $594(6 I)$ & $130(13)$ & $221(23)$ & 971 & \\
\hline \multicolumn{7}{|c|}{ Age Group (Years) } \\
\hline & $<45$ & $117(53)$ & $60(27)$ & $42(19)$ & 219 & $<0.001$ \\
\hline & $45-54$ & $126(57)$ & $49(22)$ & $45(20)$ & 221 & \\
\hline & $55-64$ & $281(54)$ & $78(15)$ & $151(29)$ & 520 & \\
\hline & $65-74$ & $263(47)$ & $78(14)$ & $200(36)$ & 556 & \\
\hline & $\geq 75$ & $158(48)$ & $25(8)$ & I 34 (4I) & 326 & \\
\hline & Not known & $23(40)$ & $6(11)$ & $10(18)$ & 57 & \\
\hline \multicolumn{2}{|c|}{ Type of Diabetes } & & & & & 0.009 \\
\hline & Type I & $53(47)$ & $32(28)$ & $29(25)$ & 114 & \\
\hline & Type 2 & $902(5 \mathrm{I})$ & $26 \mid(15)$ & $547(31)$ & 1762 & \\
\hline & Not known & $13(57)$ & $3(13)$ & $6(26)$ & 23 & \\
\hline \multicolumn{3}{|c|}{ Duration of Diabetes (years) } & & & & 0.062 \\
\hline & $0-4$ & $253(5 \mathrm{I})$ & $90(18)$ & $|4|(29)$ & 493 & \\
\hline & $5-9$ & $224(48)$ & $86(18)$ & $146(3 \mid)$ & 469 & \\
\hline & $10-14$ & $176(56)$ & $40(13)$ & $91(29)$ & 314 & \\
\hline & $15-19$ & $100(55)$ & $18(10)$ & $57(3 I)$ & 183 & \\
\hline & $\geq 20$ & $104(50)$ & $33(16)$ & $65(3 I)$ & 209 & \\
\hline & Not known & III (48) & $29(13)$ & $82(36)$ & 231 & \\
\hline \multicolumn{2}{|c|}{ Ethnic Group } & & & & & $<0.001$ \\
\hline \multicolumn{2}{|c|}{ White European } & $336(38)$ & $189(2 \mid)$ & $368(4 I)$ & 895 & \\
\hline \multicolumn{2}{|c|}{ Afro-Caribbean } & $337(64)$ & $62(12)$ & $121(23)$ & 525 & \\
\hline \multicolumn{2}{|c|}{ African } & $121(70)$ & $10(6)$ & $39(23)$ & 172 & \\
\hline \multicolumn{2}{|c|}{ Other } & $148(66)$ & $29(13)$ & $43(19)$ & 224 & \\
\hline \multicolumn{2}{|c|}{ Not known } & $26(31)$ & $6(7)$ & $11(13)$ & 83 & \\
\hline \multicolumn{2}{|c|}{ Social Class } & & & & & $<0.001$ \\
\hline \multicolumn{2}{|c|}{ Non-manual } & $292(5 \mathrm{I})$ & $82(14)$ & $202(35)$ & 576 & \\
\hline \multicolumn{2}{|c|}{ Manual } & 441 (49) & $155(17)$ & $305(34)$ & 905 & \\
\hline \multicolumn{2}{|c|}{ Not known } & $235(56)$ & $59(14)$ & $75(18)$ & 418 & \\
\hline \multicolumn{2}{|c|}{ Education } & & & & & 0.020 \\
\hline \multicolumn{2}{|c|}{ Primary } & $250(52)$ & $65(14)$ & $155(82)$ & 481 & \\
\hline \multicolumn{2}{|c|}{ Secondary } & 421 (49) & $155(18)$ & $269(31)$ & 857 & \\
\hline \multicolumn{2}{|c|}{ Technical } & $91(5 \mathrm{I})$ & $25(14)$ & $61(84)$ & 178 & \\
\hline \multicolumn{2}{|c|}{ University } & $132(53)$ & $40(16)$ & $74(30)$ & 248 & \\
\hline \multicolumn{2}{|c|}{ Not known } & $74(55)$ & $11(8)$ & $23(17)$ & 135 & \\
\hline \multicolumn{2}{|c|}{ Car Ownership } & & & & & 0.006 \\
\hline \multicolumn{2}{|c|}{ Owns Car } & 401 (48) & $134(16)$ & $290(35)$ & 833 & \\
\hline \multicolumn{2}{|c|}{ None } & $522(54)$ & $154(16)$ & $278(29)$ & 975 & \\
\hline Not 1 & & $45(50)$ & $8(9)$ & $14(15)$ & 24 & \\
\hline Hou & & & & & & $<0.001$ \\
\hline Own & & $374(56)$ & $73(\mathrm{II})$ & $208(3 \mathrm{I})$ & 670 & \\
\hline Rente & & $520(48)$ & $207(19)$ & $345(32)$ & 1089 & \\
\hline Othe & & $74(53)$ & $16(11)$ & $29(2 \mathrm{I})$ & 140 & \\
\hline
\end{tabular}

a from chi-square test after omitting 53 cases with 'not known' smoking status

regression analyses were used to evaluate differences in SF-36 scores according to smoking habit after adjusting for age, sex, duration of diabetes, whether English was the first language, social class, education, car ownership, and housing tenure. General practice was fitted as a random effect using the 'xtreg' command in Stata with the maximum likelihood option [21]. Logistic regression analyses were performed to evaluate differences in health care uti- lisation according to smoking habit, after adjusting for age, sex, ethnic group, duration of diabetes, type of diabetes, the eight SF-36 scores and the eight items of self-reported morbidity. For these analyses SF-36 scores were reduced to four categories with an additional category for 'not known' values. 
Table 2: Prevalence of current cigarette smoking by white European diabetic subjects according to age and gender in comparison with Health Survey for England data. Figures are frequencies (per cent of row total).

\begin{tabular}{|c|c|c|}
\hline Age group (years) & Smokers / Total (\%) & Health Survey For England (1998) [9] \\
\hline \multicolumn{3}{|l|}{ MEN } \\
\hline$<55$ & $39 / 117(33)$ & $30 \% a$ \\
\hline $55-64$ & $29 / 114(25)$ & $23 \%$ \\
\hline $65-74$ & $21 / 125(17)$ & $18 \%$ \\
\hline$\geq 75$ & $11 / 94(12)$ & $9 \%$ \\
\hline Not known & $1 / 5$ & \\
\hline Total & $101 / 455$ & \\
\hline \multicolumn{3}{|l|}{ WOMEN } \\
\hline$<55$ & 32 / $89(36)$ & $28 \%$ a \\
\hline $55-64$ & $21 / 95(22)$ & $25 \%$ \\
\hline $65-74$ & $23 / 133(17)$ & $19 \%$ \\
\hline$\geq 75$ & $10 / 120(8)$ & $10 \%$ \\
\hline Not known & $2 / 3$ & \\
\hline Total & $88 / 440(20)$ & \\
\hline
\end{tabular}

a figures are for 35 to 54 years

\section{Results}

There were 2,983 eligible subjects and responses were obtained from 1,899 (64\%), including 968 (51\%) nonsmokers, 296 (16\%) current smokers and 582 (31\%) exsmokers. There were 53 cases with missing or not known smoking status. The median number of respondents per practice was 57 and ranged from 10 to 232. The proportion of current smokers by practice ranged from $0 \%$ to $25 \%$. The response rate varied from $41 \%$ to $85 \%$ at different practices. There was a weak tendency for practices with higher proportions of smokers to have lower response rates (an increase of $10 \%$ in the proportion of smokers gave a $6 \%, 95 \%$ confidence interval $-1 \%$ to $13 \%$, decrease in the practice response rate, $\mathrm{P}=0.077$ ). Table 1 shows the characteristics of the sample according to smoking status. In general, the frequency of current cigarette smoking was higher in men than women, and decreased with age. Smoking was more frequent in white Europeans (men $22 \%$, women 20\%), than in African Caribbeans (men $15 \%$, women $10 \%$ ) or Africans (men $8 \%$, women $2 \%$ ). Table 2 shows age-specific rates for smoking in white European men and women in comparison with Health Survey for England data. In these diabetic subjects, smoking prevalence was generally similar to that of the general population.

Multiple logistic regression analyses with current smoking as the dependent variable (Table 3), confirmed that male gender, younger age, and white European ethnicity were independently associated with current smoking. After adjusting for these variables, there was a weak negative association of smoking and duration of diabetes. There was a strong association between current smoking and rented housing tenure. After adjusting for these confounding var- iables smoking was not associated with the type of diabetes, educational attainment, social class or car ownership.

Complete data for all scales of the SF-36 were obtained for 1415 (75\%) of subjects. Table 4 shows the differences for SF-36 scale scores between current smokers and neversmokers after adjusting for demographic and social variables and duration and type of diabetes. Even after adjusting for a wide range of confounders, current smokers had significantly lower scores (worse health status) for seven of the eight scales of the SF-36, while ex-smokers had values intermediate between smokers and non-smokers. There was no significant difference in pain scores between smokers and non-smokers. Table 5 shows the distribution of self-reported morbidity in relation to smoking status. After adjusting for demographic and socio-economic variables and duration and type of diabetes, there were no major differences between groups. However, current smokers reported a diagnosis of 'high blood pressure' slightly less frequently than non-smokers $(P=0.031)$.

Table 6 shows differences in health care utilisation between non-smokers, current smokers and ex-smokers. Odds ratios were adjusted for age, sex, ethnic group, duration and type of diabetes, social characteristics and health status. There appeared to be a fair measure of equity of access to consultations with the general practitioner, dietitian, chiropodist, or ophthalmologist. However, current smokers were less likely to have attended a hospital clinic in the last year and both smokers and ex-smokers were less likely to report attending a diabetes nurse in the last twelve months. There were no differences in the use of insulin or blood glucose monitoring according to smoking status. However, current smokers were less likely to report 
Table 3: Variables associated with cigarette smoking in diabetic subjects. Figures are frequencies (per cent of row total) and odds ratios ( $95 \%$ confidence intervals) adjusted for each of the variables shown ${ }^{\text {a }}$.

\begin{tabular}{|c|c|c|c|c|}
\hline & & Current smoker/total (\%) & Odds ratio $(95 \% \mathrm{Cl})$ & $\mathbf{P}$ value \\
\hline \multirow[t]{2}{*}{ Sex } & Men & $166 / 901(18)$ & 1.00 & 0.019 \\
\hline & Women & $130 / 945(13)$ & 0.71 (0.53 to 0.95$)$ & \\
\hline \multirow{6}{*}{ Age } & $<45$ & $60 / 219(27)$ & 1.00 & $<0.001$ \\
\hline & $45-54$ & $49 / 220(22)$ & $0.83(0.58$ to $\mathrm{I} .17)$ & \\
\hline & $55-64$ & $78 / 510(15)$ & 0.47 (0.29 to 0.79$)$ & \\
\hline & $65-74$ & $78 / 541(14)$ & $0.4 \mathrm{I}(0.26$ to 0.64$)$ & \\
\hline & $\geq 75$ & $25 / 317(8)$ & $0.18(0.11$ to 0.32$)$ & \\
\hline & Not known & $6 / 39(15)$ & 0.71 ( 0.32 to 1.57$)$ & \\
\hline \multirow[t]{5}{*}{ Ethnic Group } & White & $189 / 893(2 \mid)$ & 1.00 & $<0.001$ \\
\hline & Afro-Caribbean & $62 / 520(12)$ & $0.53(0.36$ to 0.77$)$ & \\
\hline & African & $10 / 170(6)$ & $0.12(0.06$ to 0.24$)$ & \\
\hline & Other & $29 / 220(13)$ & $0.5 \mathrm{I}$ (0.34 to 0.79$)$ & \\
\hline & Not known & $6 / 43(14)$ & 0.69 (0.27 to 1.73$)$ & \\
\hline \multicolumn{5}{|c|}{ Duration of Diabetes (years) } \\
\hline & $0-4$ & $90 / 484(18)$ & 1.00 & 0.001 \\
\hline & $5-9$ & $86 / 456(18)$ & 1.09 (0.70 to 1.69$)$ & \\
\hline & $10-14$ & $40 / 307(13)$ & 0.71 (0.54 to 0.95$)$ & \\
\hline & $15-19$ & $18 / 175(10)$ & $0.49(0.28$ to 0.85$)$ & \\
\hline & $\geq 20$ & $33 / 202(16)$ & 0.79 (0.48 to I.30) & \\
\hline & Not known & $29 / 222(13)$ & $0.73(0.48$ to I.I0) & \\
\hline \multirow[t]{3}{*}{ Housing Tenure } & Owner & $73 / 655$ (II) & 1.00 & $<0.001$ \\
\hline & Rented & $207 / 1072(19)$ & 2.02 ( 1.48 to 2.74$)$ & \\
\hline & Not known & $16 / 119(13)$ & $1.24(0.77$ to 2.00$)$ & \\
\hline
\end{tabular}

acurrent smoking was not independently associated with educational attainment, car ownership, social class or type of diabetes bdata for 53 subjects with 'not known smoking status were omitted

Table 4: SF-36 scale scores according to smoking status for diabetic subjects. Figures are mean difference (95\% confidence interval) score compared with subjects who never smoked ${ }^{\mathrm{a}, \mathrm{b}}$.

\begin{tabular}{|c|c|c|}
\hline SF-36 scale & Current smoker & Ex-smoker \\
\hline Physical functioning & $-5.6(-10.0$ to -1.2$)$ & $-4.0(-7.6$ to -0.3$)$ \\
\hline Physical role limitation & $-9.7(-16.1$ to -3.3$)$ & $-3.9(-9.2$ to 1.5$)$ \\
\hline Mental health & $-6.3(-9.3$ to -3.2$)$ & $-1.1(-3.6$ to 1.5$)$ \\
\hline Vitality & $-5.7(-9.2$ to -2.2$)$ & $-1.4(-4.3$ to 1.5$)$ \\
\hline Emotional role limitation & $-8.9(-15.5$ to -2.4$)$ & $-1.6(-7.1$ to 3.9$)$ \\
\hline Social functioning & $-5.1(-9.6$ to -0.5$)$ & $-2.2(-6.0$ to 1.6$)$ \\
\hline Pain & $-2.8(-7.2$ to 1.6$)$ & $-2.8(-6.5$ to 0.9$)$ \\
\hline General health & $-6.1(-9.7$ to -2.5$)$ & $-2.6(-5.6$ to 0.4$)$ \\
\hline
\end{tabular}

a analyses were adjusted for age, sex ethnic group, whether first language was English, social class, education, car ownership, housing tenure, duration of diabetes and type of diabetes. banalyses were based on 1415 cases with complete data for all SF-36 scales.

that a doctor had told them they had high blood pressure. Among those with high blood pressure, current smokers were less likely to report currently taking tablets for high blood pressure.

\section{Discussion}

\section{Prevalence of smoking in diabetes}

This study was carried out in a deprived part of inner London where the population includes a high proportion of ethnic minorities, particularly people of African or Caribbean descent. The prevalence of smoking among white European subjects with diabetes was similar to that seen in the general population in data from the Health Survey 
Table 5: Diabetes-related morbidity in relation to smoking status. Figures are frequencies (percent of column total).

\begin{tabular}{|c|c|c|c|c|}
\hline Morbidity & Never (968) & Current smokers (296) & Ex - smokers (582) & Odds ratio ${ }^{a}(95 \% \mathrm{Cl})$ \\
\hline Burning and numbness in feet & $395(4 I)$ & $126(43)$ & $240(4 I)$ & 1.29 (0.93 to I.79) \\
\hline Previous foot ulcer & $76(8)$ & $29(10)$ & $43(7)$ & 1.19 (0.68 to 2.07$)$ \\
\hline Previous amputation & $28(3)$ & $9(3)$ & $14(2)$ & I.07 (0.55 to 2.05$)$ \\
\hline Difficulty with eyesight & $353(36)$ & $92(3 I)$ & $182(31)$ & $1.10(0.80$ to 1.53$)$ \\
\hline Heart attack & $66(7)$ & $26(9)$ & $90(15)$ & $1.20(0.65$ to 2.20$)$ \\
\hline Stroke & $77(8)$ & $21(7)$ & $61(10)$ & $1.13(0.67$ to 1.90$)$ \\
\hline Heart trouble & $134(14)$ & $30(10)$ & $107(18)$ & $0.69(0.46$ to 1.05$)$ \\
\hline High blood pressure & $585(60)$ & $|5|(5 \mid)$ & 341 (59) & $0.79(0.63$ to 0.98$)$ \\
\hline
\end{tabular}

a odds ratio comparing current smokers with never smokers after adjusting for age, sex, duration of diabetes, ethnic group, type of diabetes, whether English was the first language, social class, housing tenure, education and car ownership

Table 6: Variations in access to health care for diabetic subjects according to smoking status. (OR, odds ratio; Cl, confidence interval).

\begin{tabular}{|c|c|c|c|c|c|c|c|}
\hline & \multirow{2}{*}{$\begin{array}{l}\text { Never smoked } \\
\begin{array}{l}\text { Frequency (\%) } \\
(968)\end{array}\end{array}$} & \multicolumn{2}{|c|}{ Current Smokers } & \multirow[t]{2}{*}{ P value } & \multicolumn{2}{|c|}{ Ex-smoker } & \multirow[t]{2}{*}{ P Value } \\
\hline & & $\begin{array}{l}\text { Frequency (\%) } \\
\text { (296) }\end{array}$ & OR $(95 \% \mathrm{Cl})$ & & $\begin{array}{l}\text { Frequency (\%) } \\
(582)\end{array}$ & OR $(95 \% \mathrm{Cl})$ & \\
\hline \multicolumn{8}{|l|}{$\begin{array}{l}\text { Utilisation in last I } 2 \\
\text { months: }\end{array}$} \\
\hline $\begin{array}{l}\text { Hospital clinic, at least } \\
\text { once }\end{array}$ & $585 / 774(76)$ & $161 / 237(68)$ & 0.59 (0.44 to 0.79$)$ & $<0.001$ & $387 / 498(78)$ & 1.25 (0.92 to 1.69$)$ & 0.153 \\
\hline GP clinic, at least once & $558 / 663(84)$ & 163/207 (79) & $0.78(0.47$ to 1.28$)$ & 0.321 & $35 \mathrm{I} / 428(82)$ & $0.91(0.61$ to 1.34$)$ & 0.624 \\
\hline Diabetes nurse & $712(74)$ & $198(67)$ & 0.70 (0.49 to 0.99$)$ & 0.046 & $380(65)$ & 0.72 (0.56 to 0.92$)$ & 0.008 \\
\hline Dietician & 476 (49) & $139(47)$ & $0.99(0.73$ to 1.35$)$ & 0.946 & $244(42)$ & $0.89(0.70$ to 1.12$)$ & 0.316 \\
\hline Chiropodist & $480(50)$ & $14 \mid$ (48) & $0.97(0.72$ to 1.31$)$ & 0.854 & $307(53)$ & 1.01 (0.74 to 1.38$)$ & 0.946 \\
\hline Ophthalmologist & $627(65)$ & $156(53)$ & $0.70(0.49$ to 1.01$)$ & 0.054 & 345 (59) & $0.91(0.73$ to 1.14$)$ & 0.423 \\
\hline \multicolumn{8}{|l|}{ Clinical Care } \\
\hline Treated with insulin & $231(24)$ & $95(32)$ & 1.32 (0.87 to 2.02$)$ & 0.195 & $150(26)$ & $1.24(0.92$ to 1.66$)$ & 0.156 \\
\hline $\begin{array}{l}\text { Uses self-monitoring } \\
\text { (blood or urine) }\end{array}$ & $777(80)$ & $232(78)$ & $0.85(0.62$ to 1.15$)$ & 0.280 & $465(80)$ & I.II (0.86 to I.44) & 0.404 \\
\hline Told BP high & $585(60)$ & $|5|(5 \mid)$ & 0.75 (0.60 to 0.93$)$ & 0.010 & 341 (59) & $0.86(0.69$ to 1.06$)$ & 0.164 \\
\hline $\begin{array}{l}\text { Treated for } \\
\text { hypertension }\end{array}$ & $484 / 585(83)$ & $101 / 151(67)$ & 0.47 ( 0.30 to 0.74$)$ & 0.001 & $267 / 34 \mid(78)$ & 0.73 (0.45 to 1.18$)$ & 0.204 \\
\hline
\end{tabular}

aadjusted for age, sex, ethnic group, duration of diabetes, type of diabetes, social class, car ownership, education, housing tenure and eight SF-36 scores. b53 cases with 'not known' smoking status were omitted from the analyses.

for England [9], while the prevalence of smoking among ethnic minority subjects was lower than in the general population. Our results show that in inner city populations with diabetes in Britain, smoking is an appreciable problem, with little evidence that people with diabetes are substantially less likely to smoke than their non-diabetic peers. We recognise that as the study population was more deprived than the general population in England, higher smoking rates might have been anticipated.

\section{Variables associated with smoking}

As in the US NHIS study [14], smoking was associated with male gender, younger age, and lower socio-economic status. In our data, housing tenure was more strongly associated with smoking than educational attainment, social class or car ownership. Measures of educational attainment and occupational social class have a complex inter-relationship with age and ethnicity, and may have less utility in a sample like ours in which $74 \%$ of subjects were aged 55 years or older. Housing tenure may have a similar significance across age and ethnic groups. Housing tenure has been shown to be associated with worse health even after adjusting for social class or household income [22]. Unlike the US report [14], which found that smoking was more common among black and Hispanic men, we found that smoking rates were lower in African Caribbean and African subjects. Low rates of smoking may be one factor which has contributed to the relatively low rate of coronary heart disease in African Caribbeans [23]. 


\begin{abstract}
Health status
Current smokers had lower SF-36 scores for all dimensions of physical and mental functioning except pain. Exsmokers had results which were intermediate between those of current smokers and never smokers. These relationships were independent of housing tenure, social class, education and car ownership. Studies in non-diabetic subjects have also shown lower SF-36 scores in smokers $[24,25]$. Prospective studies are needed to clarify the implications of this finding, but the observations suggest that smoking cessation in diabetes may lead to improvement in subjective well-being.
\end{abstract}

\section{Health care utilisation}

After adjusting for health status as a measure of need, smokers appeared to gain access to primary care on an equitable basis with non-smokers. However, there was some evidence that smokers might have less access to hospital clinic care. Smokers were also less likely to be given a diagnosis of high blood pressure, or to be treated with tablets if a diagnosis was given. These results were unexpected, and since a number of different utilisation variables were being evaluated, the results should be treated with caution. The associations were strong, giving rise to concern that some aspects of the clinical care of smokers may be unsatisfactory. An alternative explanation is that the help-seeking behaviour of smokers differs from that of non-smokers.

After completing these analyses, we analysed data from the Health Survey for England 1994 which includes data for a large representative sample of adults in England. These analyses confirmed that smokers were less likely to be aware of their hypertension, or to be treated, than nonsmokers [13]. There was some evidence that ex-smokers were more likely to be aware of their hypertension and treated. This suggested that doctors who detect hypertension in smokers may advise them to give up smoking. Nevertheless, the results from both analyses underline the importance of hypertension detection and treatment in those who continue to smoke. This is especially true in diabetic subjects. The prevalence of hypertension appears to be similar in smokers and non-smokers [26].

\section{Limitations of study}

The response rate for the study (64\%) compares favourably with other surveys conducted in inner city areas. However, we acknowledge that we cannot estimate the response rate according to ethnicity or smoking status, because this information was elicited from the study questionnaire. We relied on self-reports of smoking status which were not validated by an objective method. Selection bias and information bias would both tend to reduce, rather than inflate, estimates for smoking prevalence $[27,28]$. Non-responders to surveys of smoking habits may also have worse health status [29]. Thus the relationships identified may be under-estimated. Although the study was conducted in one part of inner London, the main findings are likely to hold elsewhere. Our results are consistent with those of the US study reported by Ford et al [14], and our findings with respect to hypertension treatment have been confirmed in the analysis of national data for the general population [13].

\section{Implications of findings}

Some evidence suggests that control of cigarette smoking does not receive a high priority in the care of people with diabetes. For example, the recent Audit Commission review of diabetes services listed as key elements of an annual clinical review in diabetes, assessment of control of blood glucose, blood pressure and serum cholesterol, but not cigarette smoking [30]. The health consequences of smoking are sometimes viewed as self-inflicted and less deserving of support. Fowler et al [31] found that in a diabetes centre setting, the uptake of smoking cessation advice was low and the relapse rate was high. They argued that providing anti-smoking advice was not cost-effective [31]. However, people with lower socio-economic status have greater nicotine dependence and experience greater social and environmental barriers to stopping smoking [32]. Smoking cessation interventions may need to be particularly intense, and therefore informed by evidence on what works.

Haire-Joshu et al [3] found that advice from doctors and other health professionals was effective at reducing smoking, particularly when a consistent message was repeatedly given by different members of staff. Even short messages may be effective, but longer periods of counselling repeated over time had more effect. There is some evidence to show that these types of intervention are effective for diabetic smokers [33]. Nicotine replacement therapy is also effective in promoting smoking cessation, increasing abstinence rates up to two-fold [34]. Clinical guidelines on smoking cessation published by the US Surgeon General emphasise the importance of gauging the patient's readiness to stop smoking [35]. Patients who are unwilling to give up smoking should be given advice which will increase their motivation to give up. Ruggiero et al [36] found that $58 \%$ of 2,056 diabetic smokers were not currently considering giving up smoking. In those who had received advice from their doctor, more were considering giving up smoking. Patients who are ready to give up smoking should be treated using interventions which have been shown to be effective, including nicotine replacement therapy when appropriate [37]. Smoking cessation interventions are considered to be highly cost-effective [37]. 


\section{Conclusions}

In an inner city, smoking in diabetes is common. People with diabetes who smoke are more likely to be disadvantaged in terms of socio-economic status, have worse health status, and may gain less access to hospital care or anti-hypertensive treatment. People with diabetes who smoke may be regarded as a vulnerable group who have special needs for intervention. For those involved in the care of people with diabetes, clinical interventions to reduce smoking have the potential to reduce social inequalities in health.

\section{List of abbreviations}

SF-36 - short form 36 questionnaire

$$
\text { US - United States }
$$

\section{Competing interests}

None declared.

\section{Authors' contributions}

JS designed the study and questionnaire; AP oversaw data collection and data entry; MG contributed to design, analysed the data and drafted the paper. All authors read and approved the paper.

\section{Acknowledgement}

This study was supported by the Charitable Foundation of Guy's and St Thomas' Hospitals.

\section{References}

I. Schumacher MC and Smith KR Diabetes in Utah among adults: interaction between diabetes and other risk factors for $\mathrm{mi}$ crovascular and macrovascular complications. Am J Public Health 1988, 78: 1 195-1201

2. Suarez $L$ and Barrett-Connor E Interaction between cigarette smoking and diabetes mellitus in the prediction of death attributed to cardiovascular disease. Am 」 Epidemiol 1984 I 20:670-5

3. Haire-Joshu D, Glasgow RE and Tibbs TL Smoking and diabetes. Diabetes Care 1999, 22:1887-98

4. Ward JD Wealthy means healthy: diabetes and social deprivation. Diabet Med 1994, I I:334-5

5. Evans JMM, Newton RW, Ruta DA, MacDonald TM and Morris AD Socio-economic status and prevalence of type $I$ and type 2 diabetes mellitus. Diabet Med 2000, I 7:478-80

6. Eachus J, Williams M, Chan P, Smith GD, Grainge M, Donovan J and Frankel $S$ Deprivation and cause specific morbidity: evidence from the Somerset and Avon survey of health. BM] 1996, 3 I 2:287-92

7. Kelly WF, Mahmood R, Kelly MJ, Turner S and Elliot K Influence of social deprivation on illness in diabetic patients. BM] 1993 307: II5-6

8. Weng C, Coppini DV and Sonksen PH Geographic and social factors are related to increased morbidity and mortality rates in diabetic patients. Diabet Med 2000, 17:612-7

9. Erens B and Primatesta P Health Survey for England. Cardiovascular Disease, 1998. Findings. London: The Stationery Office 2000, I:50-59

10. Acheson ED Independent Inquiry into Inequalities in Health. London: The Stationery Office 1998, 83-85

II. Department of Health. Smoking Kills - a White Paper on Tobacco. London: Department of Health, 1998 [http://www.doh.gov.uk/ smoke.htm] March 26th 200l

12. Kee F, Gaffney B, Little J, McConnell W, Telford AM and Watson JD Is choice of general practitioner important for patients hav- ing coronary artery investigations? Quality Health Care 1994, 3:17-22

13. Gulliford MC Low rates of detection and treatment of hypertension among current cigarette smokers. I Human Hypertension 200I, I 5:77I-3

14. Ford ES, Malarcher AM, Herman WH and Aubert RE Diabetes and cigarette smoking: findings from the 1989 National Health Interview Survey. Diabetes Care 1994, I 7:688-92

15. Office of Population Censuses and Surveys General Register Office for Scotland. 199I census: ethnic group and country of birth, Great Britain. London: HMSO 1995 ,

16. Sedgwick JEC, Gulliford MC and Powrie JK Cross-cultural comparison of need and outcome in diabetes mellitus [abstract]. Diabetic Medicine 1999, I6(Suppl I): 16

I7. Brazier JE, Harper R, Jones NM, O'Cathain A, Thomas KJ and Usherwood $T$ Validating the SF-36 health survey questionnaire: new outcome measure for primary care. BM] [992, 305:160-4

18. Gulliford $M C$ and Mahabir $D$ Social inequalities in morbidity from diabetes mellitus in public primary care clinics in Trinidad and Tobago. Soc Sci Med 1998, 46: I 37-44

19. Office of Population Censuses and Surveys. Standard occupational classification. London: HMSO 1990,

20. Stata Corporation. Obtaining robust variance estimates. In Stata user's guide release 6. College Station, Texas: Stata Press 2000, $256-$ 60

2I. In: Stata Corporation. Xtreg - fixed-, between-, and random-effects, and population-averaged linear models. In: Stata reference manual release 6: volume 4 Su-Z. College Station, Texas: Stato Press 1999, 420-40

22. Maclntyre $S$, Hiscock $R$, Kearns $A$ and Ellway $A$ Housing tenure and car access: further exploration of the nature of their relations with health in a UK setting. I Epidemiol Community Health 200I, 55:330-I

23. Balarajan $R$ Ethnic differences in mortality from ischaemic heart disease and cerebrovascular disease in England and Wales. BMJ I991, 302:560-4

24. Tillmann $M$ and Silcock I A comparison of smokers' and exsmokers health-related quality of life. J Public Health Med 1997, 19:268-73

25. Woolf SH, Rothemich SF, Johnson RE and Marsland DW Is cigarette smoking associated with impaired physical and mental functional status? An office-based survey of primary care patients. Am J Prev Med 1999, I 7: I 34-7

26. Primatesta P, Falaschetti E, Gupta S, Marmot MG and Poulter NR Association between smoking and blood pressure: evidence from the Health Survey for England. Hypertension 200I, 37: I8793

27. Difford F, Telling JP, Davies KR, Fornear JE and Reading CA Continuous opportunistic and systematic screening for hypertension with computer help: analysis of non-responders. $B M$ 1987, 294: II30-2

28. Haley NJ, Axelrad CM and Tilton KA Validation of self-reported smoking behaviour: biochemical analyses of cotinine and thiocyanate. Am J Public Health 1983, 73:1204-7

29. Barchielli $A$ and Balzi $D$ Nine year follow-up of a survey on smoking habits in Florence (Italy): higher mortality among non-responders. Int J Epidemiol 2002, 3 I: 1038-1042

30. Audit Commission. Testing Times. A review of diabetes services in England and Wales. London: Audit Commission 2000, 67

31. Fowler PM, Hoskins PL, McGill M, Dutton SP, Yue DK and Turtle JR Anti-smoking programme for diabetic patients: the agony and the ecstasy. Diabetic Med 1989, 6:698-702

32. Jarvis $M J$ and Wardle J Social patterning of individual health behaviours: the case of cigarette smoking. In 'Social Determinants of Health' (Edited by: Marmot M, Wilkinson RG) Oxford: Oxford University Press 1999, 240-255

33. Canga N, De Irala J, Vara E, Duaso MJ, Ferrer A and Martinez-Gonzalez MA Intervention study for smoking cessation in diabetic patients. Diabetes Care 2000, 23:|455-1460

34. Silagy C, Mant D, Fowler G and Lancaster T Nicotine replacement therapy for smoking cessation (Cochrane Review). In: The Cochrane Library, Issue I, 2001. Oxford: Update Software.

35. Fiore MC, Bailey WC, Cohen SJ, Michael Fiore C, Dorfman SF, Goldstein MG and Gritz ER Treating Tobacco Use and Dependence. Quick Reference Guide for Clinicians. Rockville, MD: U.S. Department of Health 
and Human Services. Public Health Service. October 2000 [http:// www.surgeongeneral.gov/tobacco/tobaqrg.htm] 26th March $200 \mathrm{I}$

36. Ruggiero L, Rossi JS, Prochaska JO, Glasgow RE, de Groot M and Drfyfoos JM Smoking and diabetes: readiness for change and provider advice. Addictive Behaviors 1999, 24:573-578

37. NHS Centre for Reviews and Dissemination Smoking Cessation: What the Health Service Can Do. Effectiveness Matters 1998;3: 1-7. [http://www.york.ac.uk/inst/crd/em31.htm] 26th March 2001

\section{Pre-publication history}

The pre-publication history for this paper can be accessed here:

http://www.biomedcentral.com/1472-6963/3/4/prepub

Publish with Bio Med Central and every scientist can read your work free of charge

"BioMed Central will be the most significant development for disseminating the results of biomedical research in our lifetime. "

Sir Paul Nurse, Cancer Research UK

Your research papers will be:

- available free of charge to the entire biomedical community

- peer reviewed and published immediately upon acceptance

- cited in PubMed and archived on PubMed Central

- yours - you keep the copyright

Submit your manuscript here:

http://www.biomedcentral.com/info/publishing_adv.asp 